\title{
Synthetic Genetic Circuits for Self-Actuated Cellular Nanomaterial Fabrication Devices
}

\author{
Tolga Tarkan Olmez, ${ }^{\dagger}$ Ebru Sahin Kehribar, ${ }^{\dagger}$ Musa Efe Isilak, ${ }^{\dagger}$ Timothy K. Lu, $^{\ddagger}$ (i) \\ and Urartu Ozgur Safak Seker* ${ }^{\dagger}$ (1) \\ ${ }^{\dagger}$ UNAM- Institute of Materials and Nanotechnology, Bilkent University, Ankara, Turkey \\ ${ }^{\ddagger}$ Synthetic Biology Center, Department of Biological Engineering, Massachusetts Institute of Technology, Cambridge, \\ Massachusetts, United States
}

\section{Supporting Information}

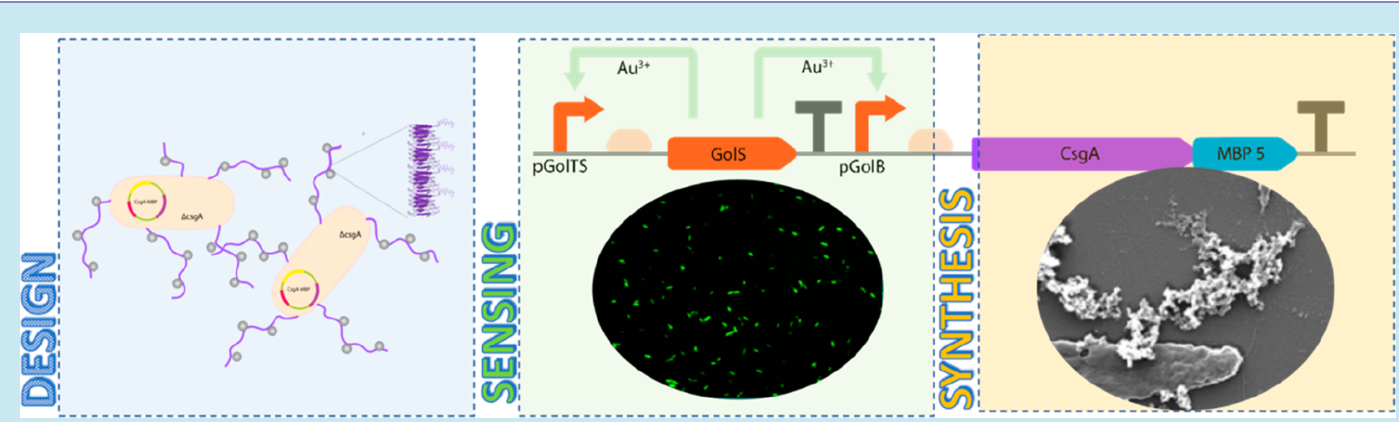

ABSTRACT: Genetically controlled synthetic biosystems are being developed to create nanoscale materials. These biosystems are modeled on the natural ability of living cells to synthesize materials: many organisms have dedicated proteins that synthesize a wide range of hard tissues and solid materials, such as nanomagnets and biosilica. We designed an autonomous living material synthesizing system consisting of engineered cells with genetic circuits that synthesize nanomaterials. The circuits encode a nanomaterial precursor-sensing module (sensor) coupled with a materials synthesis module. The sensor detects the presence of cadmium, gold, or iron ions, and this detection triggers the synthesis of the related nanomaterial-nucleating extracellular matrix. We demonstrate that when engineered cells sense the availability of a precursor ion, they express the corresponding extracellular matrix to form the nanomaterials. This proof-of-concept study shows that endowing cells with synthetic genetic circuits enables nanomaterial synthesis and has the potential to be extended to the synthesis of a variety of nanomaterials and biomaterials using a green approach.

KEYWORDS: synthetic biology, genetic circuits, biofilms, nanomaterials, whole-cell biosensors

T $\mathrm{n}$ nature, the biomineralization of hard tissues generally depends on the activity of peptides and proteins in specialized cellular compartments, e.g., silica deposition vesicles and magnetosomes. ${ }^{1,2}$ Polypeptides and proteins have been used by nature and in artificial settings as principal factors for the initiation or catalysis of biomineralization. Proteins such as phytochelatins, siderophores, and metallothioneins can bind to ion ligands, remediating their toxic effects. $^{5-7}$ Chelators, on the other hand, are metal-binding metabolites with similar characteristics and smaller sizes. However, production of these chelators in a controlled fashion is more complicated compared to the expression of metalbinding proteins and peptides. ${ }^{8}$

Alternatively, researchers have used combinatorial libraries to select short peptides that regulate biomineralization, ${ }^{9}$ based on methods such as phage display, bacterial cell surface display, yeast surface display, and directed evolution. ${ }^{10-12}$ Materialbinding peptides (MBP) have been used to synthesize zinc oxide $(\mathrm{ZnO})$, silver $(\mathrm{Ag})$, gallium arsenide ( $\mathrm{GaAs})$, titanium oxide $\left(\mathrm{TiO}_{2}\right)$, platinum $(\mathrm{Pt})$, copper $(\mathrm{Cu})$, nickel $(\mathrm{Ni})$, cobalt
(Co), silica $\left(\mathrm{SiO}_{2}\right)$, and collagen/hydroxyapatite nanomaterials. ${ }^{13-21}$ These peptides enable a biomimetic approach for environmentally responsible synthesis of nanomaterials, including hybrid material synthesis systems. ${ }^{22}$ However, one drawback of these approaches is the need for solid-state peptide synthesis, which is expensive and difficult to scale for larger area applications. ${ }^{23}$ A cell-based approach for synthesizing nanomaterials could overcome these challenges. A cellular system can provide continuous synthesis and secretion of nanomaterial templating proteins. Additionally, biochemical modifications of material synthesizing/templating proteins can be easily made by employing the tools of genetic engineering and protein engineering.

Bacterial biofilm proteins are excellent scaffolds for nanomaterial growth. Bacterial curli fibers, in particular, have great potential as bio-nanomaterial templates owing to their stability and resistance to harsh environmental conditions. ${ }^{24-26}$ Curli

Received: May 30, 2019

Published: August 16, 2019 
A

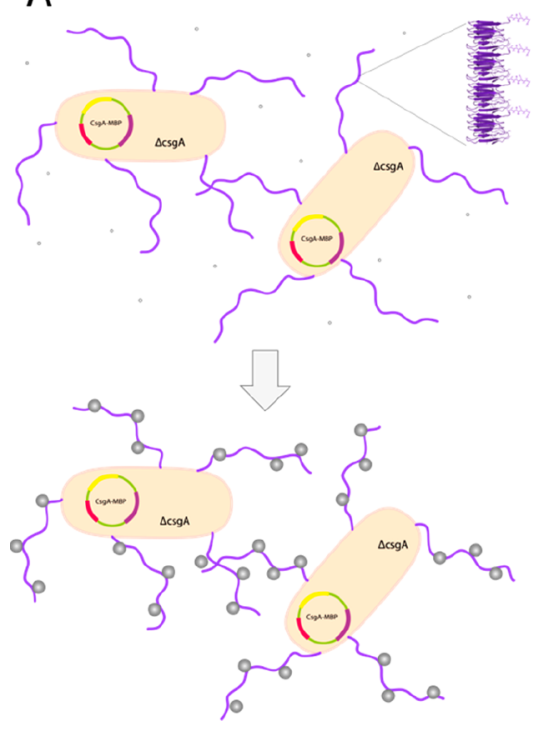

B

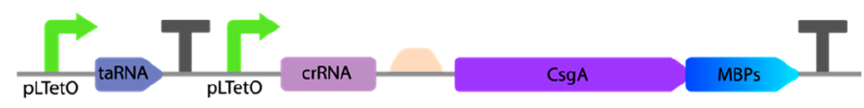

C

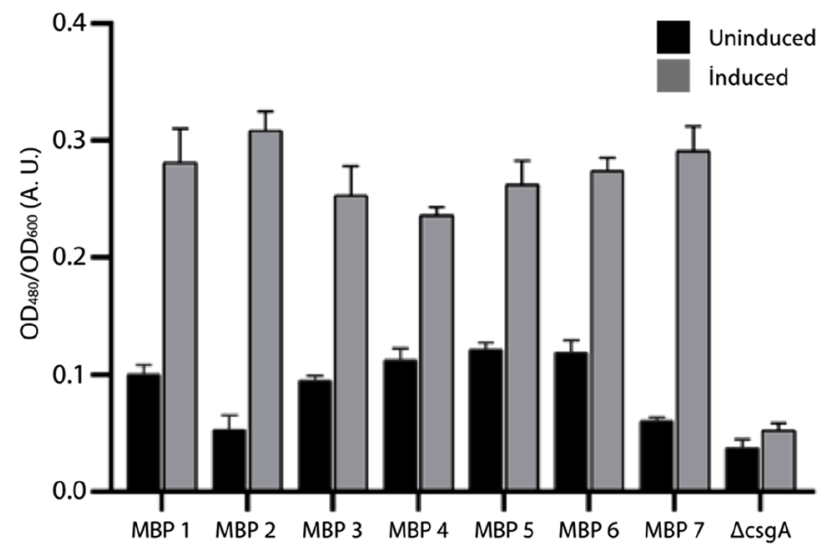

Figure 1. Formation of curli fibers displaying material-binding peptides (MBPs) for nanomaterial synthesis. (A) Schematic illustration of genetically encoded CsgA-MBP curli fiber expression and biomaterial formation. CSgA-MBP modified major curli subunits for each precursor ions are expressed under strict conditions, which are shown in this figure by purple fibers protruding from E. coli cells. Tiny gray spheres represent corresponding precursor ions that are attracted to the peptide structure of modified CsgA-MBP subunits. Nucleated ions are then assembled to form nanomaterials on the surface of each modified biofilm structure. (B) The gene circuit including a riboregulator part to use for CsgA-MBP expression. Riboregulator contains taRNA-crRNA parts which post-transcriptionally deactivates any leaky csgA-MBP mRNA product until an inducer such as aTc is added. csgA sequence was linked to MBP coding sequence via GS-linker (GGGS). (C) Congo Red staining of CsgA-MBP curli fibers.

fibers are highly ordered functional amyloids produced by Enterobacteriaceae as part of the biofilm matrix. ${ }^{27}$ The subunits of curli fibers are secreted to the extracellular environment, where they polymerize to form long, thin fibers in a process called nucleation polymerization. ${ }^{28}$ These fibers are generally 5-12 nm wide and can reach up to a couple of millimeters long. CsgA, the major curli subunit protein of Escherichia coli, is the primary constituent of the developing curli fimbriae. ${ }^{29}$ $\mathrm{CsgB}$, the minor curli subunit, is responsible for the nucleation of CsgA on the surface of the cell. ${ }^{28}$ Two adjacent curli operons ( $c s g D E F G$ and $\operatorname{csg} B A C)$ regulate the secretion of curli subunits and the inhibition of premature folding. ${ }^{29}$

These natural systems have been engineered ${ }^{30}$ and used to template nanoparticles, ${ }^{31}$ or create conductive interfaces. ${ }^{32}$ Initial attempts have been made to advance the utilization of biofilms for material synthesis and templating. However, bacterial biofilms have a great potential to be designed as a module in a self-actuated nano-/biomaterial synthesis system. Such a system can be further extended for applications in regenerative medicine, as living implants, by employing probiotic bacteria as the chassis of the system. In a selfactuated material synthesizing system, actuation could be provided by a cellular sensor induced by environmental signals. Cellular biosensors enabled by genetic circuits have been engineered to sense and respond to environmental cues. ${ }^{33}$ These engineered biosensors can be joined to genetic regulatory systems and actuator modules. ${ }^{34}$ Bacterial wholecell biosensors are easy to handle, grow and respond quickly, and are cost efficient to maintain. ${ }^{35}$

In this study, we set out to engineer cells that both synthesize nanomaterials and have ion-sensing capabilities that trigger nanomaterial formation. We designed cells that autonomously produce curli fiber-templated bio-nanomaterials by fusing curli to known material-binding peptides. The genetic fusion of selected material-binding peptides (MBPs) and the major curli subunit $\operatorname{csg} A(\operatorname{csg} A-M B P)$ in E. coli led to the display of functional peptides on the cell surface. Our constructed systems produce the corresponding functional nanomaterials by the deposition of precursors on the cell surface through functional nanofibers (CsgA-MBP). MBPs interact with a wide range of nanoparticles, such as metallic $(\mathrm{Ag}, \mathrm{Au})$, magnetic $\left(\mathrm{Fe}_{x} \mathrm{O}_{y}\right)$, or semiconductor $(\mathrm{ZnS}, \mathrm{CdS})$ materials. Precise control of material synthesis was conferred by inducible gene expression systems that express MBPs on extracellularly expressed major curli subunits. Following the synthesis of desired bio-nanomaterials, fusions of CsgA with MBP1 (Cd), MBP5 ( $\mathrm{Au})$, and MBP6 $\left(\mathrm{Fe}_{x} \mathrm{O}_{y}\right)$ circuits were improved further by incorporating genetic elements that are activated only in the presence of the respective precursor ions.

\section{RESULTS AND DISCUSSION}

Synthesis of Modified Curli Fibers. Genetically controlled synthetic biosystems can be used for the production of nanoscale materials. ${ }^{36}$ We propose engineering cells for the autonomous synthesis of biological materials using curli fiberbased nanostructures in E. coli, as represented in Figure 1A. In our proposed system, the major curli subunit CsgA coding sequence is fused with short peptide coding sequences, which results in the expression of modified curli nanofibers. These modified nanofibers have affinity for specific precursor ions that could function as a template for bio-nanomaterial growth. We achieved both spatial and temporal control in our designs that will respond exclusively to the corresponding precursor ions. Our final design includes the precursor ion that can activate curli expression and promote curli based nanomaterial synthesis at the same time. We aimed to engineer cells to synthesize cadmium sulfide, gold, and iron oxide representing, respectively, a semiconductor, a metal, and a metal-oxide. 


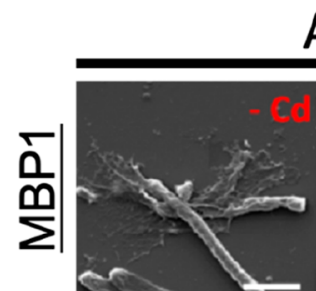

A
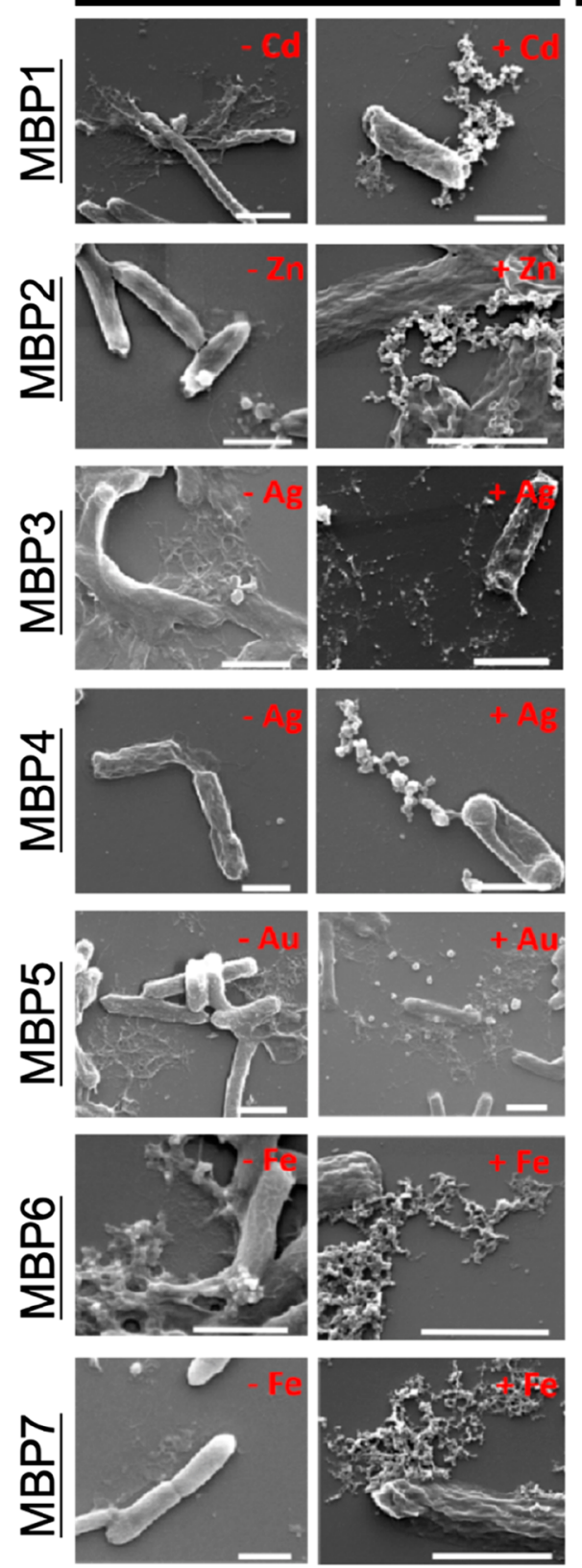

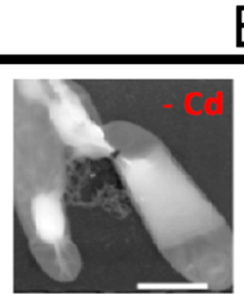

B
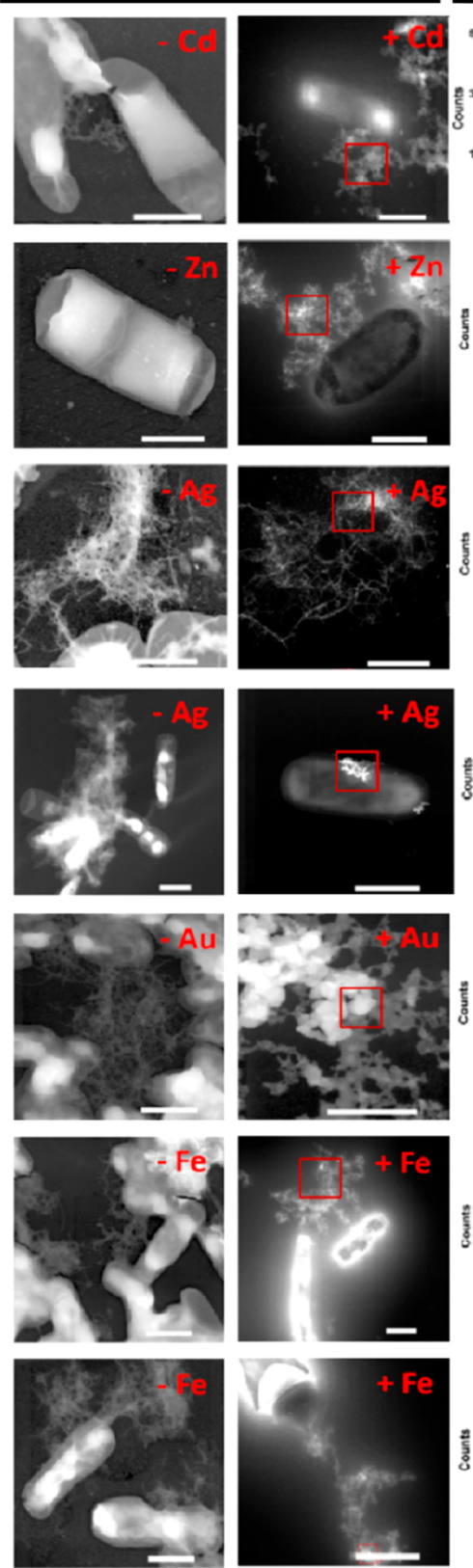
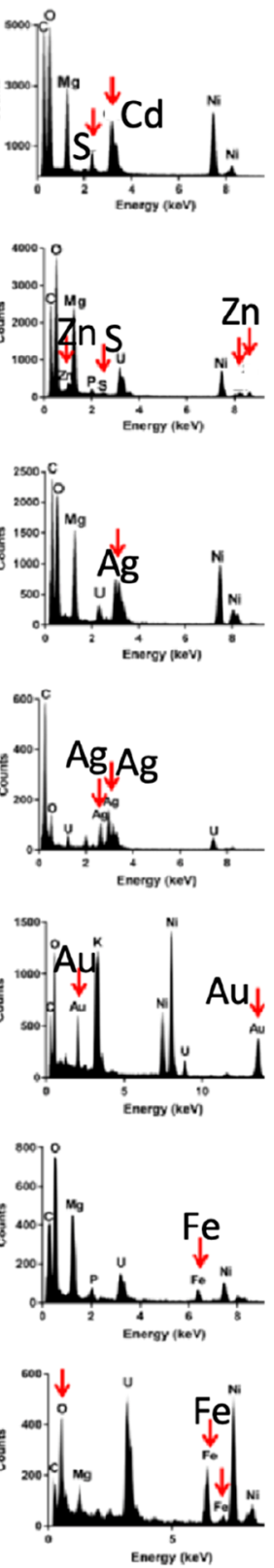

Figure 2. Synthesis of curli fiber-based nanomaterials (MBP1-7, from the left column to the right). (A) SEM imaging of materials synthesized on curli fibers. Scale bar $1 \mu \mathrm{m}$. The precursor ion that is specific for each MBP is denoted at the upper right corner of each image. Minus sign $(-)$ shows the curli fiber in the absence of precursors, while the plus sign (+) indicates precursor presence. (B) STEM-HAADF imaging of materials synthesized on curli fibers $(200 \mathrm{kV})$. White bars are $0.5 \mu \mathrm{m}$. Upper images for (A) and (B) show curli fiber production, while lower images show material production on curli fibers in the presence of precursor ions. Respective ions are noted on the upper right corner of each image. Red boxes show the selected area for energy dispersive X-ray spectroscopy (EDS) analysis. (C) EDS results of selected areas on (B) showing the elemental origin. Peaks corresponding to signals of the expected element are indicated by red arrows. All of the images were taken from three different biological samples; only representative images are included.

We exploited MBP domains from previous studies to nucleate and grow materials on curli nanofibers. We fused each of seven MBPs to the carboxyl end of CsgA protein to form biofilms with material growth capabilities. The short peptide sequences of MBPs (9-16 amino acids long) used in this study have affinity to semiconductor quantum dots $\left(\mathrm{CdS},{ }^{37}\right.$ $\mathrm{ZnS}^{38}$ ) or to metal $\left(\mathrm{Ag}^{15,39} \mathrm{Au}^{40,41}\right)$ or magnetic elements $\left(\mathrm{Fe}_{x} \mathrm{O}_{y}{ }^{42,43}\right)$. Peptide sequences were selected based on their affinity and specificity to the corresponding ions using the data provided in the previous studies. A detailed analysis of the physicochemical characteristics of these peptides is shown in Table S2.

In our genetic designs, MBP coding sequences were added downstream of the $\operatorname{csg} A$ gene. The $\operatorname{csg} A$ and $m b p$ parts were separated with a GS-linker (GGGS) in order to increase the likelihood of the independent folding of each polypeptide (Figure 1B). The csgA gene knockout strain (E. coli MG1655 $D H 5 \alpha P R O \quad \Delta c s g A)$ used throughout the study has an 
A
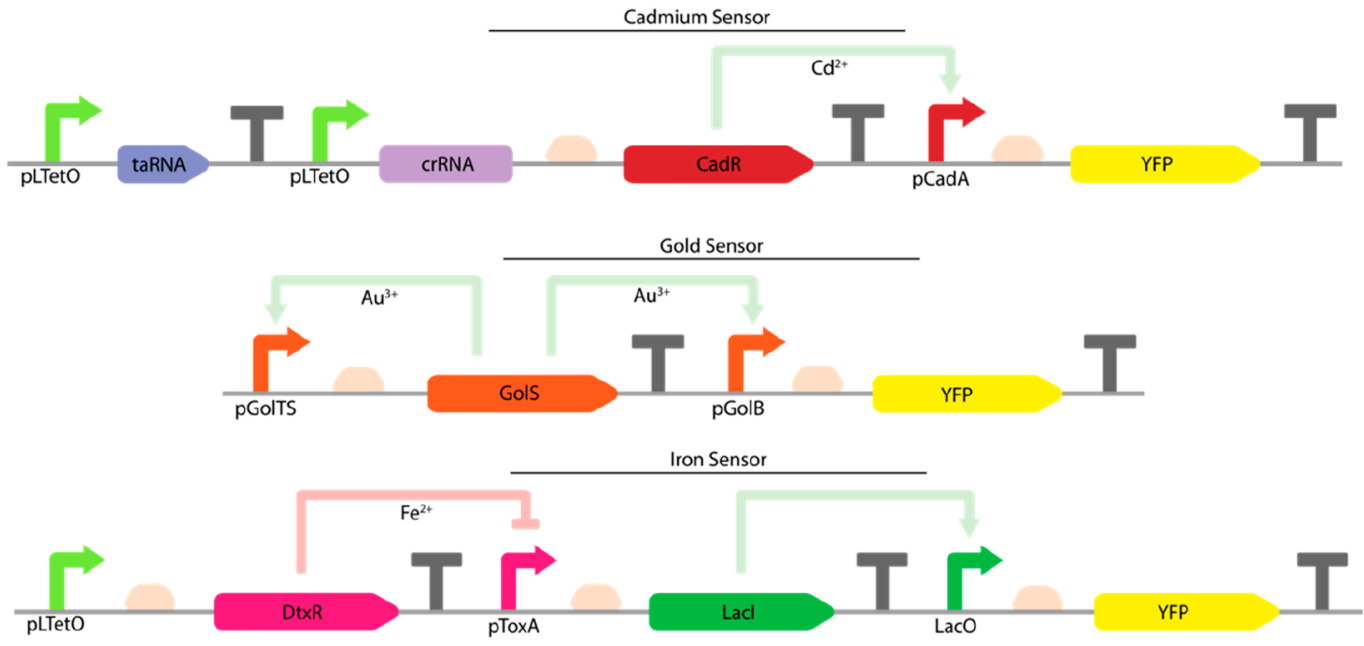

B
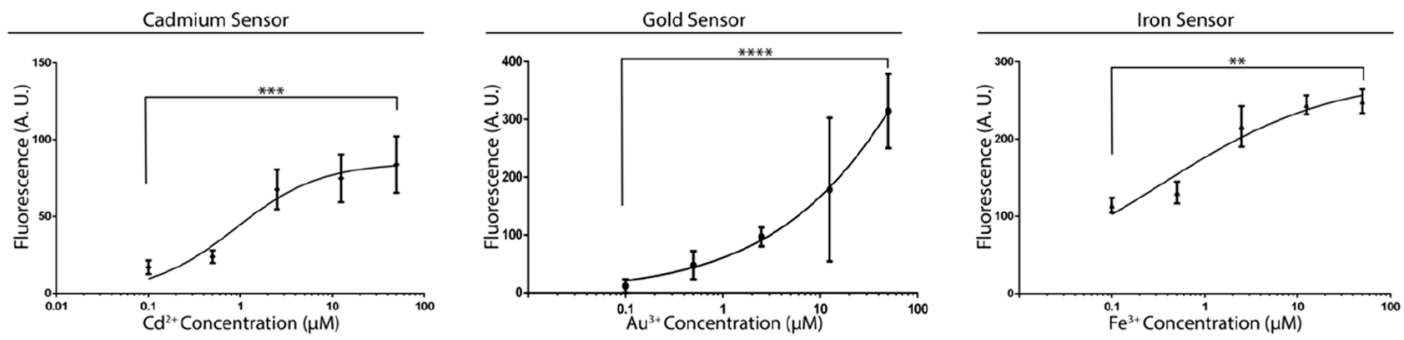

C
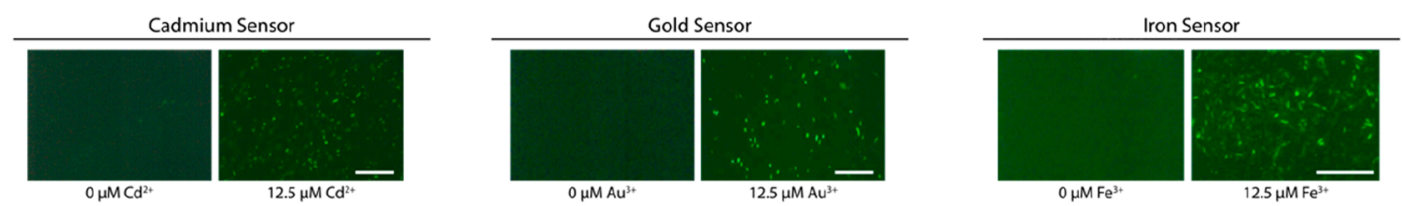

D
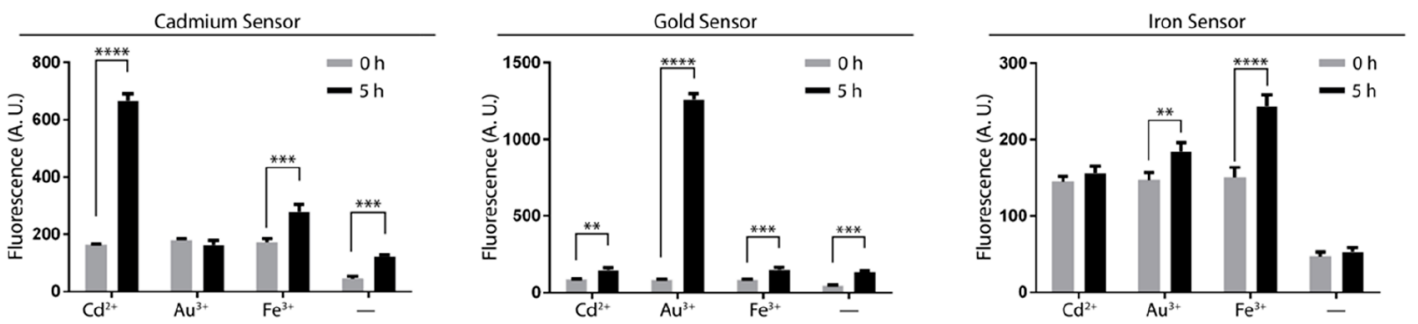

Figure 3. Characterization of material precursor sensors. (A) Design of constructs for $\mathrm{Cd}^{2+}, \mathrm{Au}^{3+}$, and $\mathrm{Fe}^{3+}$ sensors. Cadmium sensor design includes CadR which is a cadmium responsive transcription factor that regulates the expression of $p$ CadA promoter. Gold sensing is achieved by GolS protein, which regulates its own expression as well as activating $p$ GolB promoter in response to gold ion presence. Iron sensor design includes DtxR which normally represses $p$ ToxA promoter. The response was inverted by a Lacl-pLacO inverter circuit. (B) Fluorescence spectroscopy results of $\mathrm{Cd}^{2+}, \mathrm{Au}^{3+}$, and $\mathrm{Fe}^{3+}$ whole-cell sensors. For all spectroscopy experiments, an excitation and emission pair of 514-528 $\mathrm{nm}$ was used. Oneway ANOVA analysis was performed and statistical differences were indicated as $* * * p<0.001$ and $* * * *<0.0001 ; n=6$. (C) Fluorescence microscopy images of $\mathrm{Cd}^{2+}, \mathrm{Au}^{3+}$, and $\mathrm{Fe}^{3+}$ whole-cell sensors. Scale bars are $50 \mu \mathrm{m}$. (D) Cross-reactivity determination of the biosensors. Cadmium, gold, and iron ion induction was measured as fluorescence intensity at two time points to determine the specificity of each biosensor. Two-way ANOVA analysis was performed on the cell means across two sets. Statistical differences are indicated as $* * p<0.01, * * * p<0.001$ and $* * * * p<0.0001 ; n=3$. Cadmium sensor fold change values are 4.1, 0.9, 1.6 and 2.6-fold; gold sensor fold change values are 1.7, 15.0, 1.8 and 2.9fold; iron oxide sensor fold change values are 1.1-, 1.2-, 1.7-, and 1.1-fold, respectively.

OmpR234 mutation, resulting in upregulation of curli synthesizing proteins, which leads to thicker curli fibers. ${ }^{44}$ Synthesis of modified CsgA was directed by an aTc-inducible system that is already present in the pZA-tetO vector. Curli fiber expression was validated by staining cells with Congo Red. Elevated levels of Congo Red binding in induced CsgA-
MBP samples indicated curli expression on cell surfaces (Figure 1C).

\section{Characterization of Curli Fiber-Based Nanomaterials.}

The addition of short peptides to the C-terminus of CsgA may disrupt the morphology of amyloid curli fibers or even completely inhibit fiber formation. ${ }^{45}$ To ensure that the peptides have not disturbed the morphology of the CsgA-MBP 
fibers, they were investigated by scanning electron microscopy (SEM) and transmission electron microscopy (TEM). SEM images showed that all constructs expressed curli fibers that extended away from the cells and formed intense bundles (Figure 2A). The introduction of precursor ions resulted in morphological changes in curli nanofibers with sphere-like formations, indicating possible nanoparticle formation from precursor ions for all samples. The absence of particles in the untreated samples suggested that aggregates of particles were specific to their respective curli fibers. The absence of curli fibers in some individual cells visualized during imaging was probably due to sample handling, as fibers may break down into pieces or bacteria may lose their curli fibers under intense shear stress. ${ }^{46}$

The resolution of SEM imaging was not sufficient to identify firmly positioned fibers individually. Therefore, TEM imaging was used to visualize individual fibers with better clarity, and the scanning transmission electron microscopy-high angle annular dark-field imaging (STEM-HAADF) mode allowed us to achieve better contrast and lower imaging impurities (Figure 2B). For all CsgA-MBP constructs, high-resolution TEM images revealed abundant curli fiber production with morphologies resembling those of natural curli fibers and the formation of spherical particles when precursor ions were present, in correlation with SEM images. Because modified curli fibers are templates that seed nanomaterial synthesis, the growth of nanoparticles on curli nanofibers resembling beadson-a-string is an expected phenomenon (Figure 1A). All nanomaterials synthesized in the presence of precursor ions were less than $100 \mathrm{~nm}$ in diameter (Figure 2B).

The EDS module of TEM was utilized to determine the elemental origins of the samples that contained precursor ions (Figure 2C). Carbon and oxygen signals may emanate from both the grid itself and the biohybrid material, which is shown by the variable ratios of these two elements across the different samples. In all EDS graphs, the $\mathrm{Mg}$ and $\mathrm{U}$ peaks resulted from magnesium uranyl acetate used for sample staining, whereas the Ni peaks resulted from the TEM grids. Also, the peaks indicated by arrows corresponded to the presence of precursor ions, further supporting the conclusion that the synthesized nanoparticles were indeed composed of added precursor ions. CsgA-MBP3 (Ag)-expressing cells had the highest density of curli fiber formation. The difference in the level of curli fiber expression may have arisen from the distinct inherent structures of the peptides, which may influence secretion through the CsgG transporter. ${ }^{47,48}$

Material Precursor-Inducible Whole-Cell Sensor Systems. Since the proposal of the first microbial biosensor by Karube et al. in $1977,{ }^{49}$ the development of whole-cell biosensors has received intense attention. Because microbial whole-cell biosensors surpass their conventional counterparts in complexity yet have a lower cost, there is an increased need to develop advanced biological sensors. ${ }^{50}$ Microbial whole-cell biosensors generally rely on fluorescent proteins, such as GFP, or luminescent proteins, such as luciferase, to serve as reporter genes to indicate the presence of the detected substance. Other proteins, such as beta-galactosidase or toluene dioxygenases, have also been used to form arsenic sensors and cellular stress sensors, respectively. ${ }^{51} \mathrm{We}$ aimed to develop a composite system for self-actuated nanomaterial synthesis triggered by a sensor module. To develop a curli-templated nanomaterial synthesis approach, material precursor-inducible promoters were incorporated into the gene circuits. The automated synthesis of curli-MBP fibers in the presence of precursor ions can be achieved by this approach, as presented in Figure 1. In our system, CsgA-MBPs were produced in response to precursor ions potentially forming semiconductor, metallic, and magnetic materials. Initially, the functionality of the precursor sensor was characterized using yellow fluorescent protein (YFP) reporters instead of CsgA-MBPs. YFP signal intensities were tracked to determine the minimum concentration for reliable induction of each construct. The construction and activation of whole-cell sensors in E. coli are shown via fluorescence-based methods, such as fluorescence microscopy and spectroscopy, as presented in Figure 3.

Cadmium is a toxic metal-like element found in nature. CadR transcriptional activator is a cadmium-sensing protein that is produced by Pseudomonas spp. to resist the devastating effects of cadmium ions. ${ }^{52}$ For the sensor module, we used CadR protein from Pseudomonas putida, a rod-shaped, nonsporulating, Gram-negative, soil-dwelling microbe. ${ }^{53}$ CadR is a 147 amino acid long, sequence-specific DNAbinding and cadmium ion active protein from the MerR family of transcriptional regulators. C-Terminal effector-binding regions and $\mathrm{N}$-terminal helix-turn-helix DNA-binding regions are shared by multiple species of bacteria, while the effectorbinding region varies, determining the specificity for attached ions. ${ }^{54}$ In the presence of cadmium ions, CadR activates gene expression from the pCadA promoter. ${ }^{55}$ In our design, a riboregulator switch sustained the expression of CadR so that the leakiness of the promoters could be avoided. In this riboregulator-controlled expression system, a cis-repressed RNA (crRNA) controls CadR translation, and aTc induces trans-activating RNA (taRNA) expression in the cadmium sensory module. crRNA forms a stem-loop and represses CadR expression. Addition of aTc induces the expression of taRNA, leading to stem-loop unwinding in crRNA and, in turn, to CadR translation. Upon induction with cadmium, CadR activates the expression of the reporter gene under the control of pCadA promoter (Figure $3 \mathrm{~A}$ ). In order to test the response of the cadmium sensor to different $\mathrm{Cd}^{2+}$ levels, a concentration range of $\mathrm{Cd}^{2+}$ from $0 \mu \mathrm{M}$ to $50 \mu \mathrm{M}$ was utilized for the induction of the reporter gene, as the higher concentrations of $\mathrm{Cd}^{2+}$ are known to have toxic side effects. ${ }^{56,57}$ Fluorescence microscopy results showed that in the absence of $\mathrm{Cd}^{2+}$, no YFP fluorescence was observed; YFP fluorescence became more pronounced as the concentration of $\mathrm{Cd}^{2+}$ increased (Figure S24). The fluorescence intensity data revealed that $0.1 \mu \mathrm{M}$ $\mathrm{Cd}^{2+}$ was not enough to actuate a detectable fluorescence response and that the YFP signal suddenly increased between induction with $0.5 \mu \mathrm{M}$ and $2.5 \mu \mathrm{M} \mathrm{Cd}^{2+}$, in correlation with fluorescence spectroscopy (Figures 3B and S24). Therefore, a concentration range of $\mathrm{Cd}^{2+}$ between $0.5 \mu \mathrm{M}$ and $2.5 \mu \mathrm{M}$ was used to induce a more detailed pattern, and a correlation between $\mathrm{Cd}^{2+}$ concentration and the YFP signal was observed (Figure S4).

GolS is also a member of the MerR family of transcription regulators from Salmonella typhimurium that selectively interacts with gold ions. GolS induces transcription from the pGolB promoter and, upon binding to $\mathrm{Au}^{3+}$ ions, autoregulates its own expression from the pGolTS promoter. ${ }^{58} \mathrm{We}$ utilized the GolS transcription regulator to develop the gold ion sensor. Briefly, expression of GolS is autoregulated under the pGolTS promoter, while the $\mathrm{pGolB}$ promoter controls the expression of the reporter protein (Figure 3A). Upon binding to $\mathrm{Au}^{3+}$ ions, GolS induces the expression of $\mathrm{pGolB}$, as well as the reporter 
A

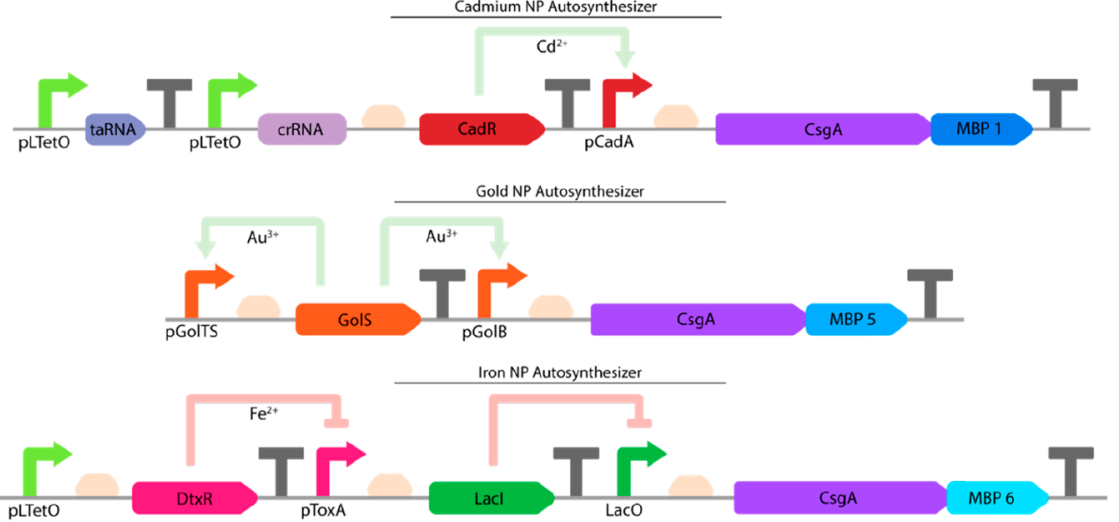

B

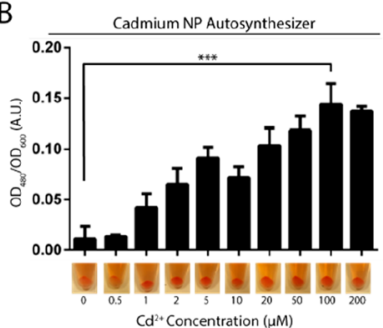

C

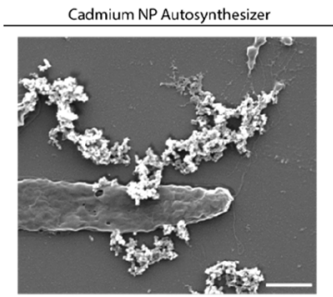

D

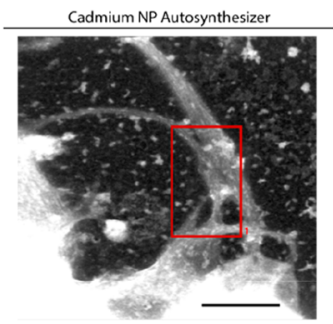

$\mathrm{E}$

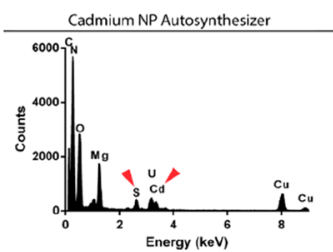

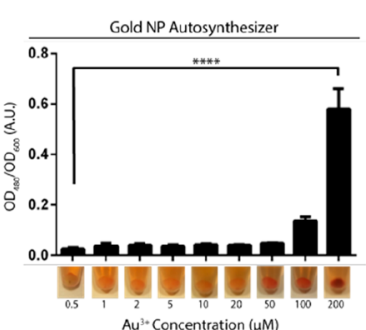

Gold NP Autosynthesizer
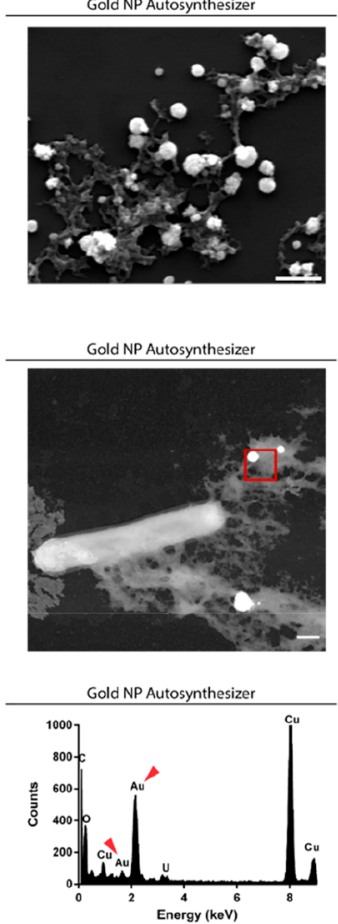

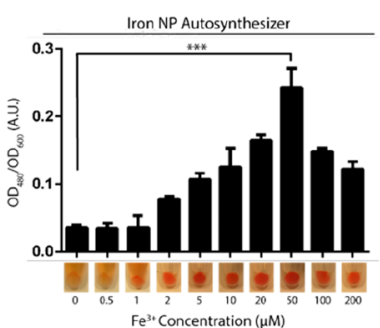

Iron NP Autosynthesizer

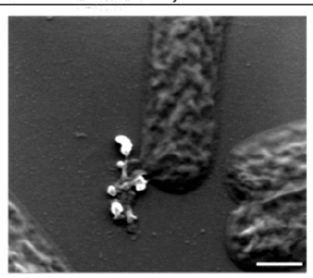

Iron NP Autosynthesizer
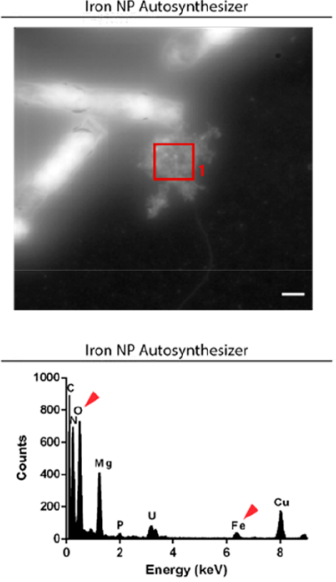

Figure 4. Nanomaterial fabrication using autosynthesizer cells. (A) Designs of constructs of material precursor-inducible curli nanofiber synthesizers for $\mathrm{Cd}^{2+}, \mathrm{Au}^{3+}$, and $\mathrm{Fe}^{3+}$ ions, respectively. (B) Congo Red staining results for synthesizers of $\mathrm{Cd}(\mathrm{CdS}), \mathrm{Au}$, and $\mathrm{Fe}\left(\mathrm{Fe} \mathrm{O}_{y}\right)$ nanoparticles. Images under each bar show the binding of Congo Red stain by the corresponding samples. For all Congo Red graphs, data represent mean \pm SD $(n=3)$. One-way ANOVA analysis was performed. Statistical differences are indicated as $* * * p<0.001$ and $* * * * p<0.0001(n=3)$. (C) SEM imaging results for synthesizers of $\mathrm{Cd}(\mathrm{CdS}), \mathrm{Au}$, and $\mathrm{Fe}\left(\mathrm{Fe}_{x} \mathrm{O}_{y}\right)$ nanoparticles. Bars are $0.5 \mu \mathrm{m}$. (D) TEM imaging results for synthesizers of $\mathrm{Cd}(\mathrm{CdS}), \mathrm{Au}$, and $\mathrm{Fe}\left(\mathrm{Fe}_{x} \mathrm{O}_{y}\right)$ nanoparticles. Bars are $0.5 \mu \mathrm{m}$. Red boxes show selected areas for EDS analysis. (E) EDS results for synthesizers of $\mathrm{Cd}(\mathrm{CdS}), \mathrm{Au}$, and $\mathrm{Fe}\left(\mathrm{Fe}_{x} \mathrm{O}_{y}\right)$ nanoparticles. EDS data was collected from the marked areas in TEM images. Red arrows indicate expected elemental peaks. Samples were collected from replicates; representative images are presented here.

protein. Therefore, the sensor construct does not include any synthetic promoters (e.g., pLtetO) and requires only $\mathrm{Au}^{3+}$ ions for induction. In order to test the activity of the sensory module, several $\mathrm{Au}^{3+}$ concentrations, ranging from $0.1 \mu \mathrm{M}$ to
$50 \mu \mathrm{M}$, were tested for their capacity to induce YFP expression. Fluorescence microscopy images revealed that induction could be observed at gold ion concentrations as low as $0.5 \mu \mathrm{M}$, while the absence of gold ions produced no 
detectable signal (Figures $3 \mathrm{C}$ and $\mathrm{S} 24$ ). $\mathrm{Au}^{3+}$ induction was quantified by fluorescence spectrophotometry, revealing a concentration-dependent induction regime (Figure 3B). The highest fluorescence intensity values were reached at $50 \mu \mathrm{M}$ $\mathrm{Au}^{3+}$ induction, while confocal images showed that the fraction of cells induced at $50 \mu \mathrm{M}$ was lower than at $12.5 \mu \mathrm{M} \mathrm{Au}^{3+}$ (Figure S6, Table S8). The increase in fluorescence may be due to the enhanced production of YFP per cell in samples to which $50 \mu \mathrm{M} \mathrm{Au}^{3+}$ ion was added, as this high concentration of $\mathrm{Au}^{3+}$ ion might compensate for the reduced proportion of YFP-expressing cells.

Diphtheria toxin repressor (DtxR), a transcriptional repressor protein whose cognate promoter region is $p$ Tox $A$, is endogenously produced in response to iron ions by the bacterium Corynebacterium diphtheria. ${ }^{59}$ Because the $d t x R$ gene and $p$ ToxA are exogenous to E. coli, DtxR is not expected to be regulated by endogenous iron-sensing mechanisms in $E$. coli, facilitating the use of DtxR transcription factor as a heterologous expression system. Despite the inherent activity of DtxR protein as a transcriptional repressor, it was converted to an activator in the circuit by integrating an inverter (Figure 3A). The inverter circuit was constructed to inhibit LacI repressor production in response to the $\mathrm{Fe}^{3+}$-triggered signal. Consequently, the addition of iron ions is expected to repress LacI production under the control of the $p$ ToxA promoter, and reducing LacI results in reporter gene expression from a $p \mathrm{LacO}$ promoter. Therefore, using a genetic signal inverter, DtxR was converted into an activator output, enabling YFP production in the presence of $\mathrm{Fe}^{3+}$ ions. In order to record the response of the iron sensor to different $\mathrm{Fe}^{3+}$ levels, a range of $\mathrm{Fe}^{3+}$ concentrations $(0.1 \mu \mathrm{M}$ to $50 \mu \mathrm{M})$ was tested, and the induction of YFP expression was evaluated. Fluorescence microscopy images revealed that the proposed iron sensor was activated by the addition of $2.5 \mu \mathrm{M}$ precursor ions, while lower concentrations of $\mathrm{Fe}^{2+}(0.1 \mu \mathrm{M}$ and $0.5 \mu \mathrm{M})$ were not enough for observable reporter activation (Figures 3C and S24). Besides, fluorescence spectrophotometer results indicated that the background fluorescence for the control groups was relatively high compared to that seen with the cadmium and gold sensors, which may be the result of circuit complexity and crosstalk (Figure 3B). Additionally, E. coli has a natural iron regulatory system directed by the Fur transcriptional activator, which may also interfere with dose-dependent response quite considerably. $^{60}$

Cross-reactivity experiments were conducted to determine the specificities of the constructed whole-cell biosensors to particular nanoparticle precursors. All ions- $\mathrm{Cd}^{2+}, \mathrm{Au}^{3+}$, and $\mathrm{Fe}^{3+}$ - were applied to induce each sensor, and the sensor cells were incubated with the ions for $5 \mathrm{~h}$ before the fluorescence signal produced by YFP was measured (Figure 3D). Cadmium sensor showed acceptable specificity to $\mathrm{Cd}^{2+}$ ions. Although, a significant increase with iron ions was observed, the increase in control group suggested the increase was caused by the leak from the circuit. The gold ion sensor reacted to cadmium and iron ions similarly to the control group, with very slight activation after $5 \mathrm{~h}$, substantiating the high specificity with which it sensed the gold nanoparticle precursors. The significant activation observed with gold ions and the high background signal might undercut the specificity of the iron nanoparticle precursor sensor. The iron nanoparticle precursor sensor produced the most significant fluorescence with iron induction and, for this reason, could be used in conjunction with the autosynthesizer in spite of the significant activation observed with gold ions and high background signal. This might arise from the usage of complicated genetic designs, addition of multiple synthetic regulators and confounding factors arising from the interaction of each of the genetic circuits. Alternatively, the iron sensor could also function as a strong generic metal sensor.

Production of Functionalized Curli Nanofibers upon Induction by Material Precursors. After constructing the whole-cell biosensors and demonstrating their responsiveness to material precursors, we integrated the modified curli material synthesis systems into the sensor constructs. The designed systems were expected to synthesize modified curli nanofibers when induced by nanomaterial precursor ions, and similar materials can nucleate on these functional nanofibers. Sensor constructs were utilized as a template to constitute the new constructs, replacing the reporter genes with the corresponding CsgA-MBPs (Figure 4A). Also, synthesized particles were characterized to analyze whether the synthesized materials were functional or not. Initially, the functionality of the cadmium sensor integrated material synthesizer was demonstrated using Congo Red staining, SEM, and TEM (Figure 4). Congo Red results indicated that $1 \mu \mathrm{M}$ of cadmium was sufficient to initiate curli synthesis. SEM and TEM images revealed curli synthesis and nanoparticle formation on curli fibers (Figure 4C,D). EDS data showed Cd and S peaks, indicating the formation of $\mathrm{CdS}$ nanoparticles, while the $\mathrm{C}, \mathrm{O}$, and $\mathrm{N}$ peaks represented the organic phase (Figure $4 \mathrm{E}$ ). In all EDS graphs, $\mathrm{Mg}$ and $\mathrm{U}$ peaks resulted from the staining method, while the grids were made from $\mathrm{Cu}$. $\mathrm{CdS}$ particles were in the range of sub-100 nm; additionally, the size of the CdS fluorescent particles was in the usual QD range, which is generally about sub-10 $\mathrm{nm}$. We observed that CdS particles emitted green fluorescence (Figure S2). To further demonstrate that green fluorescence was emitted from the nanoparticles rather than from the cells, a plasmid constitutively expressing mCherry (proD-mCherry) was introduced into the cells by cotransformation along with the cadmium curli synthesizer plasmid. Autosynthesizer cells were expected to emit red fluorescence due to mCherry expression, and the CdS nanomaterials were expected to emit green fluorescence. Confocal microscopy, utilized to visualize this phenomenon, revealed the formation of micro- and nanosized particles (Figure S5).

We employed Congo Red staining, as well as SEM and TEM, to investigate the gold sensor integrated material synthesizer and the formation of functional gold nanoparticles (Figure 4). Congo Red results showed that even $1 \mu \mathrm{M}$ of gold ion was sufficient to induce curli expression; however, at least $100 \mu \mathrm{M}$ of gold ion was needed for efficient curli synthesis (Figure 4B). Even though Congo Red data indicated a dramatic increase of gold-bearing curli fibers at $200 \mu \mathrm{M}$, the addition of $200 \mu \mathrm{M}$ of gold was partially destructive to cells, and $\mathrm{OD}_{600}$ values were affected by the high concentrations of gold (data not shown). SEM images demonstrated that gold nanoparticles formed around the curli fibers (Figure 4C). AuNPs are known to be less toxic than the $\mathrm{Au}(\mathrm{I})$ and $\mathrm{Au}(\mathrm{III})$ and the formation of AuNPs could be the reason for reduced toxicity of gold ions. Particle size distribution analysis was performed on the gold sample, and particle sizes (of around $50-150 \mathrm{~nm}$ ) were found to be distributed in a concentrationdependent manner (Figure S7). Because gold nanoparticle synthesis can be observed only at high concentrations of gold ions, the experiment was performed using precursor ion 
concentrations ranging from $20 \mu \mathrm{M}$ to $1 \mathrm{mM}$. Particle sizes ranged within an order of magnitude resulting in particle surface area differences of from $25000 \mathrm{~nm}^{2}$ to $250000 \mathrm{~nm}^{2}$. Similarly, TEM images revealed the formation of nanoparticles on curli fibers (Figure 4D), and EDS analysis peaks for $\mathrm{Au}$, in addition to organic phase elements $(\mathrm{C}$ and $\mathrm{O})$, indicated that the composition of the nanoparticles was indeed gold (Figure $4 \mathrm{E})$.

Finally, the functionality of the iron sensor integrated material synthesizer and the morphology of the formed iron nanoparticles were investigated with Congo Red staining, SEM, and TEM (Figure 4). The Congo Red assay indicated that at least $2 \mu \mathrm{M}$ of iron precursor ions was necessary to initiate curli synthesis; the addition of $50 \mu \mathrm{M}$ iron resulted in the most abundant curli induction. Higher iron concentrations reduced curli production by half, probably due to the toxic effects of elevated iron levels (Figure 4B). While iron ions show their toxic effects at high concentrations, many of the metabolic activities are turned down or off, depending on the importance of that network in bacteria. Downregulation of iron uptake mechanisms caused by high concentration of iron in bacteria is not enough to save the cells from death in the presence of $100 \mu \mathrm{M}$ iron or higher. Moreover, SEM and TEM images further supported the curli production and synthesis of iron nanoparticles upon addition of precursor ions (Figure 4C,D). In SEM and TEM images, formation of curli fibers around the cells and accumulation of particles on these curli networks was observed. To determine the material origin, we selected areas shown in Figure 4D to be the target areas for EDS analysis. EDS peaks confirmed the presence of organic components ( $\mathrm{C}$ and $\mathrm{O}$ ), as well as of the iron nanoparticles (Fe) (Figure 4E).

\section{CONCLUSIONS}

Biofilms are impressive 3D extracellular structures that provide bacteria with protection under stringent conditions. Biofilm proteins, which confer strength and robustness to these matrices, can be genetically engineered so that the biofilm gains new functions. Because a large surface area can be covered by bacterial biofilm fibers, engineering the biofilm structures for material nucleation and growth is a promising approach to creating useful new nanomaterials. We engineered CsgA, the major E. coli biofilm protein, by fusing materialnucleating peptide domains to it for biomineralization. We also coupled the material nucleation module with a precursor ion sensor, to create a cellular biosensor that processes information about the precursor ions available in the environment. Signal transduction allows the cells to secrete the corresponding engineered biofilm protein to nucleate the nanomaterial of interest. These biosensing, nanomaterial-fabricating cells synthesized modified CsgA proteins that bore the particular material they were designed for.

Initially, we picked seven MBPs from the literature in order to test the capability of curli-fused MBPs for nanoparticle synthesis. Each MBP was fused to the $\operatorname{csg} A$ gene via molecular cloning and expressed in E. coli. MBP-fused curli-producing cells synthesized nanoparticles in the presence of the respective precursor ions. We constructed sensor modules for detecting cadmium, gold, and iron nanoparticle precursor ions to develop autosynthesizers. Their characterization revealed specific sensing of the precursor cadmium, gold, and iron ions at concentrations of $2.5 \mu \mathrm{M}, 0.5 \mu \mathrm{M}$ and $2.5 \mu \mathrm{M}$, respectively. Sensory modules and CsgA-MBPs were joined to assemble the autosynthesizers that template semiconductor, metal, and magnetic nanoparticle synthesis in response to the presence of appropriate precursor ions, as demonstrated in Figure 4.

In this study, we showed that the application of genetic circuits can be extended to engineer cells designed for nanomaterial synthesis. We believe that our cellular approach to engineering sense-and-response systems can open new avenues for in vivo biomaterial synthesis. This approach can be used in environmental applications, to effectively detect and eventually remove pollutants as well as in regenerative medicine. An example can be the designer cells that are allowed to thrive in contaminated waters and specifically attract harmful ions by forming nanomaterials around biofilm structures. Resulting biomass can be separated from the environment by other means (centrifuging, flocculation, autoaggregation etc.) and thereby remediating contaminated waters. In short, our designer cells can be combined with other synthetic constructs to achieve novel functions.

\section{MATERIALS AND METHODS}

Genetic Designs and Cloning of Fusion Peptide Constructs. CsgA-MBP (major curli subunit csgA-materialbinding peptides) constructs were cloned as follows. The $\operatorname{csg} A$ gene was retrieved from the genome of wild-type $E$. coli MG1655. Cells were grown overnight, and genomic DNA was isolated according to the manufacturer's guidelines (QIAamp genomic DNA kit). Genomic DNA was amplified using Q5 DNA polymerase (New England Biolabs, M0941S) with primers targeting the $\operatorname{csg} A$ open reading frame. MBP sequences were fused to the $3^{\prime}$ ends of the $\operatorname{csg} A$ gene by additional PCR amplification. Primer sequences used for PCR reactions are listed in Table S3. Resulting DNA fragments and the pZA-tetO vector backbone were restriction digested by high fidelity KpnI (New England Biolabs, R3142) and MluI (New England Biolabs, R3198) enzymes to create sticky ends. DNA fragments were run on a $1 \%$ agarose gel, and target DNA bands were extracted using QIAquick Gel Extraction Kit (Qiagen, USA). DNA was ligated by T4 DNA ligase (New England Biolabs, M0202), using the suggested protocol. Ligated plasmid products were then used to transform a chemically competent strain of E. coli $(D H 5 \alpha P R O \Delta c s g A)$ by the standard heat shock transformation protocol. The transformed colonies were selected on chloramphenicol agar plates (final concentration of chloramphenicol, $35 \mu \mathrm{g} / \mathrm{mL}$ ). Unless otherwise stated, all incubations in this study were performed at $37{ }^{\circ} \mathrm{C}, 225 \mathrm{rpm}$. For all constructs, selected colonies were verified by Sanger sequencing (Genewiz, USA). Individual chromatograms can be found in Figures S8-S14. The amino acid and nucleotide sequences of each design are listed in Tables S1, S6, S8, and S9.

The gene fragments to form the ion sensors sensitive to gold, cadmium, and iron oxide precursor ions (transcription factors and related downstream promoters) were synthesized (Genewiz, USA), then the resulting fragments were amplified to form overlapping ends and ligated to PZA-tetO vector using the Gibson assembly protocol. ${ }^{61}$ Design maps for all sensors are shown in Figure 3A. Primers used for sensor constructs are listed in Table S4. Iron oxide sensor designs include an inverter genetic part obtained from the registry of standard biological parts (Part ID: BBa_Q01121, iGEM). Yellow fluorescent protein (YFP) was used as the reporter gene for all sensors. $E$. coli DH5 $\alpha$ PRO $\triangle$ csgA was transformed with gold- and 
cadmium-related constructs, whereas E. coli DH5 $\alpha$ csgA was transformed with iron oxide-related constructs because constitutively active tetR in DH5 $\alpha P R O$ leads to constitutive expression of DtxR. Detailed chromatograms of selected Sanger sequencing-verified colonies can be found in Figures S15-S17. Designs of curli nanomaterial synthesizer constructs are shown in Figure 4A. Gibson assembly was utilized to assemble fragments on the pZA vector, as indicated above. For each construct, the corresponding csgA-MBP fragment and sensor fragment were PCR amplified to create overlapping ends for the Gibson assembly reaction. Primers used for cloning are listed in Table S5. For all constructs, selected colonies were verified by Sanger sequencing, and individual chromatograms can be found in Figures S18-S20.

Congo Red Staining. Congo Red staining was used to detect amyloid structures. Anhydrotetracycline (aTc, final concentration: $100 \mathrm{ng} / \mathrm{mL}$ )-induced bacterial cultures were grown in LB medium on a shaking incubator at $100 \mathrm{rpm}, 30$ ${ }^{\circ} \mathrm{C}$ for 2 days. Then $1.5 \mathrm{~mL}$ of bacterial culture was centrifuged at $3000 \mathrm{~g}$, the supernatant was carefully decanted, and the bacteria were washed once with $\mathrm{ddH}_{2} \mathrm{O}$. A solution of Congo Red, a diazo dye that binds to amyloid structures, was added in equal amounts to each tube (final concentration $20 \mu \mathrm{g} / \mathrm{mL}$ ) and resuspended. After $30 \mathrm{~min}$ of incubation at $30{ }^{\circ} \mathrm{C}$, the tubes were centrifuged, and cells were imaged. A dosedependent curli production assay (Congo Red) was also performed using the sensor plasmids with some modifications. First, overnight cultures were diluted $1: 100$ and incubated at $30{ }^{\circ} \mathrm{C}$ until $\mathrm{OD}_{600}$ values reached up to 0.8 , and then material precursor ions were added, as described in the Material Synthesis section. After $12 \mathrm{~h}$ of precursor ion addition, $\mathrm{Na}_{2} \mathrm{~S}$ was added. Then the samples were incubated at $100 \mathrm{rpm}, 30$ ${ }^{\circ} \mathrm{C}$ for two more days before we performed the Congo Red assay as described above.

Crystal Violet Staining. Crystal violet was used to visually assess the adherence of the cells to solid surfaces. The cultures for each construct were grown overnight at $30{ }^{\circ} \mathrm{C}$ in $\mathrm{LB}$ medium and then diluted 1:100 in M63 medium, supplemented with magnesium sulfate $(1 \mathrm{mM})$ and glucose $(20$ $\mathrm{mM}$ ). Two milliliters of culture was placed in each well of a 24well plate and incubated for 2 days at $100 \mathrm{rpm}, 30{ }^{\circ} \mathrm{C}$. After incubation, the medium was decanted, and the wells were washed three times with $\mathrm{ddH}_{2} \mathrm{O}$ to reduce the background signal by removing free and loosely bound cells from the wells. Then $200 \mu \mathrm{L}$ of a $0.1 \%$ crystal violet aqueous solution was added to the wells, and plates were incubated for $15 \mathrm{~min}$. The wells were washed with $\mathrm{ddH}_{2} \mathrm{O}$ until the decanted medium was colorless, to remove excess crystal violet dye. Plates were left to dry at room temperature prior to black and white $(\mathrm{B} / \mathrm{W})$ photography.

Material Synthesis by Modified Curli Fibers. After curli production was induced by the addition of aTc $(100 \mathrm{ng} / \mathrm{mL})$, the cultures were incubated in LB medium for 2 days to express modified curli. Subsequently, cells were centrifuged at $3000 \mathrm{~g}$, the media was replaced with fresh media, and a particular protocol for each ion was applied to initiate material synthesis. We added $\mathrm{CdCl}_{2}(1 \mathrm{mM})$ into the media for CdS synthesis and incubated the culture at room temperature for 30 min. Then, $\mathrm{Na}_{2} \mathrm{~S}(1 \mathrm{mM})$ was slowly added to the media, and cultures were incubated at $+4{ }^{\circ} \mathrm{C}$ for $12 \mathrm{~h}$. The same protocol was utilized for $\mathrm{ZnS}$, replacing $\mathrm{CdCl}_{2}$ with $\mathrm{ZnCl}_{2}$. For gold nanomaterial synthesis, $\mathrm{HAuCl}_{4}(5 \mu \mathrm{M})$ was added to the media, and cultures were incubated in the dark at room temperature for $36 \mathrm{~h}$. We utilized the same protocol for $\mathrm{Ag}$ synthesis with $\mathrm{AgNO}_{3}(4 \mu \mathrm{M})$. For iron oxide synthesis, $\mathrm{FeCl}_{3}$ $(1 \mathrm{mM})$ was added to the media, and cultures were incubated for $30 \mathrm{~min}$ at room temperature, then at $+4{ }^{\circ} \mathrm{C}$ for $90 \mathrm{~min}$.

Microscopy Imaging. For scanning electron microscopy (SEM) imaging studies, silica wafers were washed with acetone and $\mathrm{ddH}_{2} \mathrm{O}$ to obtain clean surfaces. Following the addition of the samples on wafers, they were then incubated in fixation solution ( $2.5 \%$ glutaraldehyde in $1 \times \mathrm{PBS}$ ) at $+4{ }^{\circ} \mathrm{C}$, overnight. Next, samples were incubated in ethanol solutions of increasing concentration (40\%, 70\%, 96\%, and 100\%) for 1 $\mathrm{h}$ at each concentration at room temperature and then airdried for $1 \mathrm{~h}$ at room temperature. Dried samples were placed in a precision etching coating system (PECS) and sputter coated $(5 \mathrm{~nm})$ with an Au-Pd alloy (the gold-binding MBP5 samples were coated with chromium). We visualized samples with SEM (FEI Quanta, USA) at $5 \mathrm{keV}$ electron power. Transmission electron microscopy (TEM) studies were conducted to visualize the particles at a higher resolution. After the material synthesis, $15 \mu \mathrm{L}$ of samples was placed on a parafilm surface, and an EMS Ni grid with Formvar/C support (300 mesh) was placed on top of the sample. After 1 min of incubation, excess fluid on the surface was removed by touching the side of the grid to a powderless tissue paper. Three rounds of $\mathrm{ddH}_{2} \mathrm{O}$ cleaning were followed by staining with $2 \%$ magnesium uranyl acetate for $30 \mathrm{~s}$ to improve image contrast before imaging under TEM (FEI Tecnai, USA). TEM electron acceleration power was $200 \mathrm{keV}$. Energy dispersive Xray spectroscopy (EDS) analysis was also performed to identify material composition in selected areas (EDAX, USA).

Fluorescence images for material sensors (cadmium, gold, and iron oxide sensors) were captured via fluorescence microscopy (Scope Axio A1, Zeiss, Germany). After induction, $6 \mu \mathrm{L}$ of samples was placed on a glass slide, a mounting agent was added to protect the fluorescent signal (Fluoromount Aqueous Mounting Medium, Sigma, USA), and samples were covered with a coverslip. We used a Fs38 filter set to detect green fluorescence. Confocal laser scanning microscopy (LSM 510, Carl Zeiss, Germany) was used to assess gold sensor induction and fluorescence from the cadmium particleattached curli nanofibers. Images were acquired with a Plan Apo 63 oil immersion objective lens (numerical aperture: $1.40-0.60)$. The green signal was detected by excitation at 488 $\mathrm{nm}$ laser excitation line (Ar) and collection in the range of 509-515 nm. Z-stacking images were postprocessed via maximum intensity projection into a single image.

Induction of Precursor-Induced Material Sensitive Systems. The bacterial cultures were grown overnight at 37 ${ }^{\circ} \mathrm{C}$ to induce the YFP-harboring plasmids (cadmium YFP, gold YFP, and iron oxide YFP). Afterward, the cultures were diluted 1:100 into fresh LB medium in a 96-well microtiter plate. LB was used for growth at all times. Concentration gradients of 0.1 $\mu \mathrm{M}, 0.5 \mu \mathrm{M}, 2.5 \mu \mathrm{M}, 12.5 \mu \mathrm{M}$, and $50 \mu \mathrm{M}$ were selected with six replicates of each concentration. Cadmium sensor constructs were induced with aTc $(100 \mathrm{ng} / \mathrm{mL})$. Cultures were incubated for an additional $5 \mathrm{~h}$ at $37{ }^{\circ} \mathrm{C}$ prior to measurements. The microtiter plate was placed in a plate reader (SpectraMax M5, USA) and measured with an excitation/emission wavelength pair of 514-528 nm. All fluorescence values were $\mathrm{OD}_{600}$ normalized. Error bars indicate the standard deviations for all measurements. For precursor ion-inducible functional curli synthesizer constructs, a similar protocol was used, such that the precursor ion induction 
concentrations were $0.1 \mu \mathrm{M}, 0.5 \mu \mathrm{M}, 2.5 \mu \mathrm{M}, 12.5 \mu \mathrm{M}, 50 \mu \mathrm{M}$, $100 \mu \mathrm{M}$, and $200 \mu \mathrm{M}$ for each ion.

Cross-reactivity of Precursor Ions. In cross-reactivity experiments, we incubated three material-inducible whole-cell sensor constructs (cadmium YFP, gold YFP, and iron oxide YFP) with the other two ions, which were not expected to induce the third sensor. $50 \mu \mathrm{M}$ of the corresponding ion was selected as the induction concentration, and YFP fluorescence was measured as indicated above at two time points, the beginning of the experiment and after $5 \mathrm{~h}$ of incubation. Bacteria were grown in LB medium, and background fluorescence was subtracted from each fluorescence reading. The negative control was E. coli DH5 $\alpha$ PRO $\Delta c s g A$ with no ions added to the media.

\section{ASSOCIATED CONTENT}

\section{S Supporting Information}

The Supporting Information is available free of charge on the ACS Publications website at DOI: 10.1021/acssynbio. 9 b00235.

Biochemical characteristics of material-binding peptides; oligonucleotide primers, nucleotide sequence of genetic parts, DNA sequencing results of all the constructs; functional characterization of MBP fusion proteins; confocal analysis of nanosized particles; detailed characterization of gold-inducible sensor via confocal microscopy analysis; gold nanoparticle size control by precursor ion addition; fluorescence imaging of $\mathrm{Cd}-\mathrm{Au}$ and $\mathrm{Fe}$ sensor with respect to precursor ion concentration (PDF)

\section{AUTHOR INFORMATION}

\section{Corresponding Author}

*E-mail: urartu@bilkent.edu.tr.

\section{ORCID}

Timothy K. Lu: 0000-0002-3918-8923

Urartu Ozgur Safak Seker: 0000-0002-5272-1876

\section{Author Contributions}

U.O.S.S. conceived the idea, U.O.S.S., T.T.O., and T.K.L. designed the experiments. T.T.O., E.S.K., and M.E.I. carried out the experiments. The authors have written the manuscript together.

\section{Notes}

The authors declare the following competing financial interest(s): UOSS is co-founder of Synbiotic, TKL is a cofounder of Senti Biosciences, Synlogic, Engine Biosciences, Tango Therapeutics, Corvium, BiomX, and Eligo Biosciences. TKL also holds financial interests in nest.bio, Ampliphi, and IndieBio.

\section{ACKNOWLEDGMENTS}

This study was supported by TUBITAK (Grant Nos. $114 \mathrm{M} 163$ and 115Z217). U.O.S.S. acknowledges the TUBAGEBIP Award.

\section{REFERENCES}

(1) Tesson, B., Lerch, S. J. L., and Hildebrand, M. (2017) Characterization of a new protein family associated with the silica deposition vesicle membrane enables genetic manipulation of diatom silica. Sci. Rep. 7, 13457.

(2) Kwon, S., Kim, B. J., Lim, H. K., Kang, K., Yoo, S. H., Gong, J., Yoon, E., Lee, J., Choi, I. S., Kim, H., and Lee, H. S. (2015)
Magnetotactic molecular architectures from self-assembly of betapeptide foldamers. Nat. Commun. 6, 8747.

(3) Roehrich, A., and Drobny, G. (2013) Solid-state NMR studies of biomineralization peptides and proteins. Acc. Chem. Res. 46, 21362144.

(4) Sakaguchi, T., Janairo, J. I. B., Lussier-Price, M., Wada, J., Omichinski, J. G., and Sakaguchi, K. (2017) Oligomerization enhances the binding affinity of a silver biomineralization peptide and catalyzes nanostructure formation. Sci. Rep. 7, 1400.

(5) Neilands, J. B. (1995) Siderophores: structure and function of microbial iron transport compounds. J. Biol. Chem. 270, 2672326726.

(6) Cobbett, C. S. (2000) Phytochelatins and their roles in heavy metal detoxification. Plant Physiol. 123, 825-832.

(7) Cobbett, C., and Goldsbrough, P. (2002) Phytochelatins and metallothioneins: roles in heavy metal detoxification and homeostasis. Annu. Rev. Plant Biol. 53, 159-182.

(8) Rauser, W. E. (1999) Structure and function of metal chelators produced by plants: the case for organic acids, amino acids, phytin, and metallothioneins. Cell Biochem. Biophys. 31, 19-48.

(9) Tamerler, C., and Sarikaya, M. (2009) Genetically designed peptide-based molecular materials. ACS Nano 3, 1606-1615.

(10) Sarikaya, M., Tamerler, C., Jen, A. K., Schulten, K., and Baneyx, F. (2003) Molecular biomimetics: nanotechnology through biology. Nat. Mater. 2, 577-585.

(11) Briggs, B. D., and Knecht, M. R. (2012) Nanotechnology meets biology: peptide-based methods for the fabrication of functional materials. J. Phys. Chem. Lett. 3, 405-418.

(12) Chen, C. L., and Rosi, N. L. (2010) Peptide-based methods for the preparation of nanostructured inorganic materials. Angew. Chem., Int. Ed. 49, 1924-1942.

(13) Seker, U. O., Zengin, G., Tamerler, C., Sarikaya, M., and Demir, H. V. (2011) Assembly kinetics of nanocrystals via peptide hybridization. Langmuir 27, 4867-4872.

(14) Golec, P., Karczewska-Golec, J., Los, M., and Wegrzyn, G. (2012) Novel ZnO-binding peptides obtained by the screening of a phage display peptide library. J. Nanopart. Res. 14, 1218.

(15) Naik, R. R., Stringer, S. J., Agarwal, G., Jones, S. E., and Stone, M. O. (2002) Biomimetic synthesis and patterning of silver nanoparticles. Nat. Mater. 1, 169-172.

(16) Whaley, S. R., English, D. S., Hu, E. L., Barbara, P. F., and Belcher, A. M. (2000) Selection of peptides with semiconductor binding specificity for directed nanocrystal assembly. Nature 405 , 665-668.

(17) Sano, K., Sasaki, H., and Shiba, K. (2005) Specificity and biomineralization activities of Ti-binding peptide-1 (TBP-1). Langmuir 21, 3090-3095.

(18) Chiu, C. Y., Li, Y., Ruan, L., Ye, X., Murray, C. B., and Huang, Y. (2011) Platinum nanocrystals selectively shaped using facet-specific peptide sequences. Nat. Chem. 3, 393-399.

(19) Banerjee, I. A., Yu, L., and Matsui, H. (2003) Cu nanocrystal growth on peptide nanotubes by biomineralization: size control of $\mathrm{Cu}$ nanocrystals by tuning peptide conformation. Proc. Natl. Acad. Sci. U. S. A. $100,14678-14682$.

(20) Dickerson, M. B., Sandhage, K. H., and Naik, R. R. (2008) Protein- and peptide-directed syntheses of inorganic materials. Chem. Rev. 108, 4935-4978.

(21) Lee, J. Y., Choo, J. E., Choi, Y. S., Park, J. B., Min, D. S., Lee, S. J., Rhyu, H. K., Jo, I. H., Chung, C. P., and Park, Y. J. (2007) Assembly of collagen-binding peptide with collagen as a bioactive scaffold for osteogenesis in vitro and in vivo. Biomaterials 28, 42574267.

(22) Seker, U. O., Sharma, V. K., Akhavan, S., and Demir, H. V. (2014) Engineered peptides for nanohybrid assemblies. Langmuir 30, 2137-2143

(23) Made, V., Els-Heindl, S., and Beck-Sickinger, A. G. (2014) Automated solid-phase peptide synthesis to obtain therapeutic peptides. Beilstein J. Org. Chem. 10, 1197-1212. 
(24) Taglialegna, A., Lasa, I., and Valle, J. (2016) Amyloid structures as biofilm matrix scaffolds. J. Bacteriol. 198, 2579-2588.

(25) Reches, M., and Gazit, E. (2003) Casting metal nanowires within discrete self-assembled peptide nanotubes. Science 300, 625627.

(26) Lamour, G., Nassar, R., Chan, P. H. W., Bozkurt, G., Li, J., Bui, J. M., Yip, C. K., Mayor, T., Li, H., Wu, H., and Gsponer, J. A. (2017) Mapping the broad structural and mechanical properties of amyloid fibrils. Biophys. J. 112, 584-594.

(27) Barnhart, M. M., and Chapman, M. R. (2006) Curli biogenesis and function. Annu. Rev. Microbiol. 60, 131-147.

(28) Hammer, N. D., Schmidt, J. C., and Chapman, M. R. (2007) The curli nucleator protein, $\mathrm{CsgB}$, contains an amyloidogenic domain that directs CsgA polymerization. Proc. Natl. Acad. Sci. U. S. A. 104, 12494-12499.

(29) Evans, M. L., and Chapman, M. R. (2014) Curli biogenesis: order out of disorder. Biochim. Biophys. Acta, Mol. Cell Res. 1843, $1551-1558$

(30) Onur, T., Yuca, E., Olmez, T. T., and Seker, U. O. S. (2018) Self-assembly of bacterial amyloid protein nanomaterials on solid surfaces. J. Colloid Interface Sci. 520, 145-154.

(31) Seker, U. O., Chen, A. Y., Citorik, R. J., and Lu, T. K. (2017) Synthetic biogenesis of bacterial amyloid nanomaterials with tunable inorganic-organic interfaces and electrical conductivity. ACS Synth. Biol. 6, 266-275.

(32) Kalyoncu, E., Ahan, R. E., Olmez, T. T., and Safak Seker, U. O. (2017) Genetically encoded conductive protein nanofibers secreted by engineered cells. RSC Adv. 7, 32543-32551.

(33) Saltepe, B., Kehribar, E. S., Su Yirmibesoglu, S. S., and Safak Seker, U. O. (2018) Cellular biosensors with engineered genetic circuits. ACS Sens. 3, 13-26.

(34) Yagi, K. (2007) Applications of whole-cell bacterial sensors in biotechnology and environmental science. Appl. Microbiol. Biotechnol. $73,1251-1258$

(35) Daunert, S., Barrett, G., Feliciano, J. S., Shetty, R. S., Shrestha, S., and Smith-Spencer, W. (2000) Genetically engineered whole-cell sensing systems: coupling biological recognition with reporter genes. Chem. Rev. 100, 2705-2738.

(36) Jungmann, R., Renner, S., and Simmel, F. C. (2008) From DNA nanotechnology to synthetic biology. HFSP J. 2, 99-109.

(37) Mao, C., Flynn, C. E., Hayhurst, A., Sweeney, R., Qi, J., Georgiou, G., Iverson, B., and Belcher, A. M. (2003) Viral assembly of oriented quantum dot nanowires. Proc. Natl. Acad. Sci. U. S. A. 100, 6946-6951

(38) Zhou, W., Schwartz, D. T., and Baneyx, F. (2010) Single-pot biofabrication of zinc sulfide immuno-quantum dots. J. Am. Chem. Soc. 132, 4731-4738.

(39) Cui, Y., Wang, Y., Liu, R., Sun, Z., Wei, Y., Zhao, Y., and Gao, $\mathrm{X}$. (2011) Serial silver clusters biomineralized by one peptide. ACS Nano 5, 8684-8689.

(40) Brown, S., Sarikaya, M., and Johnson, E. (2000) A genetic analysis of crystal growth. J. Mol. Biol. 299, 725-735.

(41) Tan, Y. N., Lee, J. Y., and Wang, D. I. (2010) Uncovering the design rules for peptide synthesis of metal nanoparticles. J. Am. Chem. Soc. 132, 5677-5686.

(42) Lower, B. H., Lins, R. D., Oestreicher, Z., Straatsma, T. P., Hochella, M. F., Jr., Shi, L., and Lower, S. K. (2008) In vitro evolution of a peptide with a hematite binding motif that may constitute a natural metal-oxide binding archetype. Environ. Sci. Technol. 42, $3821-3827$.

(43) Barbas, C. F., Rosenblum, J. S., and Lerner, R. A. (1993) Direct selection of antibodies that coordinate metals from semisynthetic combinatorial libraries. Proc. Natl. Acad. Sci. U. S. A. 90, 6385-6389.

(44) Vidal, O., Longin, R., Prigent-Combaret, C., Dorel, C., Hooreman, M., and Lejeune, P. (1998) Isolation of an Escherichia coli $\mathrm{K}-12$ mutant strain able to form biofilms on inert surfaces: involvement of a new ompR allele that increases curli expression. J. Bacteriol. 180, 2442-2449.
(45) Van Gerven, N., Goyal, P., Vandenbussche, G., De Kerpel, M., Jonckheere, W., De Greve, H., and Remaut, H. (2014) Secretion and functional display of fusion proteins through the curli biogenesis pathway. Mol. Microbiol. 91, 1022-1035.

(46) Wang, L., Keatch, R., Zhao, Q., Wright, J. A., Bryant, C. E., Redmann, A. L., and Terentjev, E. M. (2018) Influence of type I fimbriae and fluid shear stress on bacterial behavior and multicellular architecture of early Escherichia coli biofilms at single-cell resolution. Appl. Environ. Microbiol. 84, DOI: 10.1128/AEM.02343-17.

(47) Nguyen, P. Q., Botyanszki, Z., Tay, P. K., and Joshi, N. S. (2014) Programmable biofilm-based materials from engineered curli nanofibers. Nat. Commun. 5, 4945.

(48) Taylor, J. D., Zhou, Y., Salgado, P. S., Patwardhan, A., McGuffie, M., Pape, T., Grabe, G., Ashman, E., Constable, S. C., Simpson, P. J., Lee, W. C., Cota, E., Chapman, M. R., and Matthews, S. J. (2011) Atomic resolution insights into curli fiber biogenesis. Structure 19, 1307-1316.

(49) Karube, I., Matsunaga, T., Mitsuda, S., and Suzuki, S. (1977) Microbial electrode BOD sensors. Biotechnol. Bioeng. 19, 1535-1547.

(50) Shimomura-Shimizu, M., and Karube, I. (2009) Applications of microbial cell sensors. Adv. Biochem. Eng./Biotechnol. 118, 1-30.

(51) Roggo, C., and van der Meer, J. R. (2017) Miniaturized and integrated whole cell living bacterial sensors in field applicable autonomous devices. Curr. Opin. Biotechnol. 45, 24-33.

(52) Whiteley, M., Bangera, M. G., Bumgarner, R. E., Parsek, M. R., Teitzel, G. M., Lory, S., and Greenberg, E. P. (2001) Gene expression in Pseudomonas aeruginosa biofilms. Nature 413, 860-864.

(53) Nikel, P. I., Martinez-Garcia, E., and de Lorenzo, V. (2014) Biotechnological domestication of pseudomonads using synthetic biology. Nat. Rev. Microbiol. 12, 368-379.

(54) Brown, N. L., Stoyanov, J. V., Kidd, S. P., and Hobman, J. L. (2003) The MerR family of transcriptional regulators. FEMS Microbiol. Rev. 27, 145-163.

(55) Brocklehurst, K. R., Megit, S. J., and Morby, A. P. (2003) Characterisation of CadR from Pseudomonas aeruginosa: a Cd(II)responsive MerR homologue. Biochem. Biophys. Res. Commun. 308, 234-239.

(56) White, C., and Gadd, G. M. (1998) Accumulation and effects of cadmium on sulphate-reducing bacterial biofilms. Microbiology 144, $1407-1415$

(57) Sousa, C., Kotrba, P., Ruml, T., Cebolla, A., and De Lorenzo, V. (1998) Metalloadsorption by Escherichia coli cells displaying yeast and mammalian metallothioneins anchored to the outer membrane protein LamB. J. Bacteriol. 180, 2280-2284.

(58) Wei, W., Zhu, T., Wang, Y., Yang, H., Hao, Z., Chen, P. R., and Zhao, J. (2012) Engineering a gold-specific regulon for cell-based visual detection and recovery of gold. Chem. Sci. 3, 1780-1784.

(59) Kunkle, C. A., and Schmitt, M. P. (2003) Analysis of the Corynebacterium diphtheriae $\mathrm{DtxR}$ regulon: identification of a putative siderophore synthesis and transport system that is similar to the Yersinia high-pathogenicity island-encoded yersiniabactin synthesis and uptake system. J. Bacteriol. 185, 6826-6840.

(60) Chen, Z., Lewis, K. A., Shultzaberger, R. K., Lyakhov, I. G., Zheng, M., Doan, B., Storz, G., and Schneider, T. D. (2007) Discovery of Fur binding site clusters in Escherichia coli by information theory models. Nucleic Acids Res. 35, 6762-6777.

(61) Gibson, D. G., Young, L., Chuang, R. Y., Venter, J. C., Hutchison, C. A., 3rd, and Smith, H. O. (2009) Enzymatic assembly of DNA molecules up to several hundred kilobases. Nat. Methods 6, $343-345$ 